\title{
Cara, Cor, Corpo (especulação sobre a intuição feminina)
}

\section{Mariza Corrêa*}

(Maio, 1980)

O ditado popular "quem vê cara não vê coração" é uma sábia afirmativa: ao mesmo tempo que reconhece a cara como um elemento da definição social das pessoas, nega o sistema de classificações baseado nas aparências. Cara sendo entendida aqui como uma palavra que resume uma aprendizagem social longa $e$ minuciosa que nos permite, com um olhar, classificar uma pessoa, concentrando nesse olhar uma série de dados que aparecem comumente separados nas estatísticas ou nos formulários que preenchemos sob qualquer pretexto - $e$ vários que não aparecem. Sexo, idade, estado "civil, profissão, cor (às vezes).

Um homem (sexo) de cerca de 40 anos (idade), branco (cor), todo vestido de branco, é presumivelmente um médico (profissão) e também presumivelmente casado, já que este é o estado civil que parece acompanhar bem os outros sinais, todos indicativos de respeitabilidade social, ostentados por este personagem. Uma mulher (sexo), sem idade definida, negra (cor), vestindo uma saia de chita $e$ usando chinelas havaianas $e$ camiseta, é presumivelmente uma empregada doméstica, e seu estado civil, como sua idade, é ambíguo, havendo a presunção ou expectativa não só de uma fieira do filhos como de que a identidade do pai, ou pais, deles, seja igualmente ambígua. Estes exemplos são certamente extremados - além de suporem o olho de um expectador que tem lá suas razóes para interpretar de tal maneira estes sinais.

* In memorian (1945-2016). Foi fundadora do Núcleo de Estudos de GêneroPagu e professora do departamento de antropologia, ambos da Universidade Estadual de Campinas (Unicamp), Campinas, SP, Brasil. 
Nas relações cotidianas lidamos com um número muito maior de elementos, e elementos muito mais sutis, internos a estas categorias mais gerais que definem prima facie o perfil social de uma pessoa, sua persona. Ainda assim, apesar de tão gerais, estas categorias nos permitem começar a refletir sobre como uma série de sinais aparentemente neutros em si mesmos assume num determinado contexto social uma conotação que transborda a sua definição pura e simples. Isto é, como o modo de vestir o corpo, a cor ou o sexo deste corpo, sua idade, e o conjunto assim produzido, podem levar a deduções sobre preferências sexuais $e$ formas de (des)organização familiar, entre outras coisas.

Alguns pesquisadores em ciências sociais tem se dedicado não só a verificar as expectativas deste tipo, que regem o comportamento das pessoas em suas relações de todos os dias, mas também a observar como a inversão destas expectativas (isto é, se o homem de branco for, por exemplo, um barbeiro ou a mulher negra uma antropóloga) gera conflitos, na forma de agressão as pessoas que literalmente não (re)conhecera o seu lugar. ${ }^{1}$ Estas inversões podem ser "para cima" (quando uma pessoa que supúnhamos ser socialmente 'menos', revela-se como sendo "mais": a mulher negra), ou "para baixo" (o "médico"/barbeiro). Em ambos os casos, há presunção $e$ aceitação de uma hierarquia social na qual as pessoas estão alocadas e a reação, ao se descobrir "a verdade" será provavelmente uma realocação dos erroneamente definidos nas categorias a que pertencem "de fato", sem que a escala em si mesma, parâmetro da primeira definição, seja posta em questão.

A situação se complica um pouco quando estas definições "equivocadas" ocorrem, em grupos de interação constante, como a família por exemplo. Aí a suposição é de pertinência ao mesmo círculo de valores e escapar dele significa não só desmentir a igualdade supostamente compartilhada pelos membros do grupo,

\footnotetext{
1 Ver, por exemplo, Goffman (1959 e 1967) ou Garfinkel (1967), que também narra belos exemplos de conflitos familiares criados pela quebra das regras mais simples do relacionamento cotidiano.
} 
como questionar a hierarquia que esta "igualdade" tornava invisível.

O exemplo da infidelidade feminina esclarece melhor este ponto.

Quando uma mulher trai seu marido, não é só a revelação de uma nova preferência afetiva que está em jogo mas também, em primeiro lugar, a súbita visibilidade do que é precisamente esperado de cada um pelos outros membros familiares, expectativas que até então pareciam ser aceitas em comum por todos eles: mulher = esposa \& mãe. E é, em segundo lugar, a revelação de sua posição como ser subordinado ao marido, subordinação essa que ate ser contestada poderia estar cuidadosamente escondida nas dobras do cotidiano, na própria vivência dos papeis de mãe e dona de casa, que exigem da mulher um constante exercício de poder na esfera doméstica. $\mathrm{O}$ quanto esta contestação é real pode ser avaliado pela frequência com que a infidelidade da mulher é aceita como justificativa de seu assassinato pelo marido. A infidelidade masculina não parece por em questão esta situação de dominação/subordinação, antes a reforça e pode por isso ser aceita sem que haja a quebra dos vínculos familiares.

Todos estes exemplos parecem suficientemente banais para que nos reconheçamos neles, ou para que eles encontrem um eco, uma ressonância, em nossa experiência própria ou conhecida. E é justamente esta (suposta) familiaridade do mundo em que vivemos que nos permite construir uma série de imagens sociais a respeito das pessoas com quem convivemos. A tal ponto que elas nos parecem naturais e não socialmente construídas, a tal ponto que podemos "esquecer" que todas estas imagens foram aprendidas (na família, na escola, na igreja, através dos jornais, do rádio, da televisão, etc.) e que elas fazem sentido dentro de um determinado tipo de sociedade, aquela na qual vivemos, mas que talvez parecessem absurdas em outro contexto. Assim como nos pareceria absurdo, por exemplo, pensar que no momento do parto fosse o pai do recém-nascido quem devesse receber as maiores atenções e quem, logo após, mereceria um período de 
repouso, a tal ponto nos parece natural ser a mãe a quem devemos atender com maior cuidado.

As sociedades tribais, frequentemente pensadas como mais próximas do mundo da natureza do que as sociedades industrializadas, ao observar a couvade cumprem com ela uma etiqueta rigorosamente cultural, que estabelece de forma visível os vínculos sociais entre o pai e a criança. Ao passo que a nossa sociedade, em geral associada ao mundo da cultura, reduz, no momento do parto, a mulher à sua condição natural mais primitiva: a de responsável pela reprodução da espécie. Todos os rituais associados a maternidade (desde o controle da natalidade, passando pela gravidez, pelo aborto e pela burocracia hospitalar, que isola a fatura mãe de seu parceiro na procriação, até a comemoração do dia das mães) em nossa sociedade, parecem servir como reforço do atributo biológico principal da mulher: a capacidade de gerar novos seres humanos. Este é seu atributo biológico principal porque a distingue enquanto sexo, a diferencia do sexo masculino, embora pudéssemos ir longe na discussão de se foi ou não socialmente que as espécies evoluíram e se diferenciaram no processo de surgimento da assim chamada raça humana.

Sexo não deve ser aqui confundido com sexualidade, embora o seja correntemente. A castidade, assim como o homossexualismo, define preferências sexuais, expressam a forma como cada um deseja viver a sua sexualidade, de forma independente do sexo biológico com o qual nasceu. Talvez esta confusão habitual entre sexo e sexualidade seja o que nos leva a atribuir a mulher a função de procriadora como seu destino sobre a terra. Confusão que aponta para a dificuldade que sentimos, no mundo ocidental, em classificar sem hierarquizar, isto é, em observar diferenças sem transformá-las em desigualdades. ${ }^{2}$ Esta é uma dificuldade antiga e que parece enraizada na nossa história

2 Isto tem implicações teóricas mais amplas que não serão tratadas aqui, entre elas o questionamento de boa parte da história e da Antropologia. Ver, por exemplo, Dumont (1967 e 1977) e Deleuze (1972 e 1978). 
pelo menos desde o surgimento do Estado, esta entidade que, ironicamente, teria nascido para por fim aos conflitos entre os homens- já que as mulheres estavam mais ocupadas no aperfeiçoamento de técnicas que tornariam mais aprazível a vida nesta terra: na invenção da cerâmica, na domesticação de animais, no plantio e na colheita de víveres, etc. Alguns autores tem observado como o dogma religioso da imaculada, conceição da concepção sem pecado, por uma virgem - que prevalece nos países colonizados sob a religião católica, é compatível tanto com uma sociedade patriarcal, onde a exploração sexual das mulheres das camadas submetidas da população é aceitável, como com a visão da mulher como um ser perigoso. ${ }^{3}$

Isto é, como a mulher é, ao mesmo tempo, responsável pela procriação e destinada à castidade. Seria possível pensar que este dogma, ou mito, da nossa sociedade é portanto um dos responsáveis pela manutenção de uma contradição básica na socialização da mulher sob o catolicismo: manter-se virgem, sendo mãe. A exceção a virgindade, como comportamento desejado $e$ normativo da mulher, é aberta apenas para a maternidade legítima, quer dizer, para um pai-espírito, superior e talvez por isso mesmo também distante e desvinculado de seus filhos.

Isto não quer dizer que as imagens de mulher socialmente produzidas sob este mito sejam unívocas, mas sim que mesmo o 'desvio' será absorvido como parte da definição do 'normal', sem lhe causar qualquer dano, sem colocá-lo em questão. A imagem da virgem-mãe pode ser a origem de uma reprodução direta, 'adequada' ao modelo - a esposa fiel sendo de certa forma uma 'virgem': avara com sua sexualidade e pródiga com os frutos de seu sexo. Ou, a reprodução dela originada pode aparecer truncada, embora utilize os mesmos elementos do modelo em contextos onde poderíamos imaginar que eles não caberiam. A prostituta, pródiga porque distribui sua sexualidade, é também avara, já que cobra pelo uso dela. Sua virgindade aparece assim como que deslocada, porque ao invés de ter sido posta a serviço

${ }^{3}$ Cf. Leach (1969) e Boxer (1975). 
da reprodução da espécie, será desperdiçada justamente no âmbito do que é negado à virgem-mãe no mito, ó âmbito do prazer. A prostituição, assim, não põe em questão o mito desde que a dupla moral, sexual esteja era vigência: virgindade $e$ monogamia para as mulheres destinadas a serem mães socialmente legitimadas, prazer entre aspas para as outras, reduto de uma sexualidade incompatível com o casamento em termos simbólicos.

Da mesma forma, e em termos mais concretos, o fato de a esposa ter um emprego - 'trabalhar fora' - outro desvio aparente do comportamento normativo, pode não questionar em nada aquela relação de dominação/subordinação, não só porque seu trabalho é em geral menos recompensado do que o trabalho equivalente de um homem (mas nem sempre), mas porque também aí há uma duplicidade envolvida - neste caso a chamada dupla jornada de trabalho. Isto é, além do trabalho 'fora', a esposa deve cumprir com o trabalho dentro do lar. Não é à toa que a um homem nunca se pergunta se ele 'trabalha fora': o trabalho é o indicador por excelência do perfil, da cara social, da persona do homem em nossa sociedade.

$\hat{E}$ o que ele faz, ou deixa de fazer, que o define; a mulher sendo definida, antes pelo que é: esposa (dedicada ou infiel), mãe (descuidada ou extremosa), dona de casa (ordeira ou relaxada), enfim, mulher. Mas este ser da mulher, produzido dentro de uma sociedade onde o fazer é a norma, torna-se uma incongruência. ${ }^{4}$ Talvez por isso, cada vez mais acentuadamente, os opostos dos valores tradicionalmente associados ao ser feminino (passividade, fraqueza, submissão, etc. ad nauseam) estão emergindo na definição de uma nova face da mulher. Mas será essa cara tão nova assim? Ou será que, como a lua, esse outro lado da nossa face social esteve sempre aí, a espera de uma oportunidade para se fazer ver?

4 Ver minha análise da implementação legal deste 'ser mulher' em nossa sociedade. A reflexão sobre as imagens de mulher deve muito ao estímulo das discussões com Julia, Leticia, Monica, Monica, Renata e Verena em nossa pesquisa coletiva sobre essas imagens. 
Desde Mauss, passando por Clastres e Boltanski, até Bourdieu e Foucault, o corpo humano tem sido percebido como um repositório de conhecimentos, como fonte de saber ou como expressão das relações vigentes numa sociedade. Tem sido observado que existe uma gramática corporal feita de signos, gestos, vestes, de toda uma gama de elementos não verbais, diferenciados conforme a pertinência do sujeito que os utiliza a um sexo, a um grupo ou a uma classe social. Já é um lugar comum em termos sociológicos falar na utilização de elementos visuais diferenciadores por grupos sociais que desejam marcar sua presença como singular, o que leva às vezes à uma extensão tão inesperada de seu uso que, ironicamente, a intenção original se perde (por exemplo, o uso de tênis ou de "jeans" pelos adolescentes). Também comum é a observação de que estas marcas são socialmente determinadas, seja pela classe social, seja pela idade, sexo ou etnia dos membros de um grupo. Mas não é tão comum refletir que, como sugere Bateson (1973:75), numa sociedade onde a dominação é um par semântico inseparável da submissão, os indivíduos membros dessa sociedade aprenderão, pelo menos implicitamente, ambos os padrões vigentes $e$ os expressarão de uma maneira ou de outra. Isto sugere que os elementos que poderiam entrar na composição de uma gramáticacorporal do sexo feminino serão utilizadas estrategicamente $e$ conforme a pertinência sexual e/ou social dos interlocutores.

Por exemplo, uma mulher pode utilizar sua aprendizagem de um papel "submisso" em relação a seu marido, mas usará seu conhecimento do papel de "dominador" em sua relação com uma empregada doméstica ou com os filhos. Mas ainda está para ser visto como reagirá em relação a um empregado do sexo masculino, socialmente seu subordinado e sexualmente (supostamente) seu superior.

Podemos supor então que o que é considerado sinal pertinente a uma gramática do sexo feminino, definindo uma conduta sexual "adequada", varia enormemente conforme a situação onde este sinal seja adotado e provavelmente incorpora sinais que à primeira vista pertenceriam a uma gramática corporal 
do sexo masculino. Em suma, a mulher é passiva numa relação, não em todas, o que não significa que ela não seja estruturalmente definida como passiva, nem que esta passividade estrutural deixe de ser individualmente assumida e se transforme em seu modo de ser mais essencial, se se pode dizer assim. Apesar de essa precaução teórica antecipar que as imagens de mulher produzidas em nossa sociedade são infinitamente mais complexas e refinadas do que a definição comum, de "submissão" deixa entrever, é possível, mesmo numa língua muito rica em expressões idiomáticas, observar as regras gramaticais que a orientam.

No entanto, temos estado até agora tão ocupadas em definir esta gramática - já razoavelmente delineada - que vamos deixando escapar da analise os detalhes mais delicados, as formas mais sutis em que se expressam as relações entre os sexos. Por enquanto só a literatura de ficção tem se ocupado delas, mas talvez seja importante começar a pelo menos tentar mapear este território de pequenas percepções no qual as mulheres se movem a maior parte do tempo, território invisivel para os homens, ou para a grande maioria deles. Algumas mulheres já começam a falar a respeito das fantasias sexuais que elaboram como contraponto (complemento, compensação?) de suas relações sexuais concretas, outras exploram ha mais tempo o tecido delicado dos sonhos, esta vasta região em que vivemos a maior parte do nosso tempo. ${ }^{5}$ Mas uma boa parte deste território, o das pequenas maldades, da destruição sistemática do outro através de pequenos mecanismos de percepção e controle é ainda um tema tabu mesmo para as mulheres que tentam transformar em palavras essa aguda sensibilidade sobre o outro lado da subordinação que não atende pelo nome de obediência ou submissão. ${ }^{6}$

Todas aquelas categorias mais gerais que utilizamos para classificar as pessoas, e que deram início a esta reflexão, estão permeadas por outros tipos de informação, não tão facilmente apreensíveis ou analisáveis. $\mathrm{E}$ apesar de certamente muito

5 Ver, por exemplo, N. Friday (1974) o Doris Lessing (1969).

6 Não se trata aqui apenas da 'jararaca', lembrada por Peter Fry (1974). 
importantes como indicadores, como parâmetros "objetivos" das relações, ou das proibições de relacionamento em nossa sociedade, elas são insuficientes para dar conta dos subtons que nossa cara, como resumo de um conjunto de símbolos socialmente definidos, revela e esconde. Não se trata da "fofoca" enquanto mecanismo de controle social, mas de algo diferente $e$ que a informa. ${ }^{7}$

Num seminário sobre sexualidade na Fundação Carlos Chagas em São Paulo, onde um grupo de mulheres discutíamos ura texto de Luce Irigaray sobre Freud, apareceu de repente a expressão "intuição feminina" ${ }^{8}$ Assim mesmo, entre aspas, já que se trata de um conceito pouco explorado que não tem o estatuto de categoria cientifica. A expressão surgiu quando falávamos sobre o papel privilegiado que o olhar como forma de conhecimento tem em nossa sociedade (teoria vem do grego theastai: olhar, observar), e como esse olhar não é apenas categórico, classificatório, mas também hierarquizante. Isto é, quando olhamos algo ou alguém, não só o enquadramos em alguma categoria mas ao mesmo tempo o definimos como superior ou inferior em relação a outra coisa ou a outrem. Ou talvez as próprias categorias que temos à nossa disposição estejam já carregadas de sinais positivos ou negativos. Tudo isto provocado pela discussão que Luce faz do ensaio "A Feminilidade", de Freud, onde ele apresenta um menino que ao descobrir a menina, a descobre como portadora de uma falta, isto é, como desigual e não como diferente, como inferior e não como complementar.

Isso nos levou a especular sobre a possibilidade de que, assim como um cego desenvolve uma maior sensibilidade auditiva, uma mais fina discriminação entre tons de voz, por exemplo, também a mulher, nas sociedades onde lhe é vedado ou

\footnotetext{
7 Ver a fascinante discussão de M.Gluckman (1963) sobre a fofoca.

8 O texto de Luce é "La tache aveugle d'un vieux rêve de symétrie" (1974). Estavam neste seminário Carmen, Cristina, Ivone, Jeannel Marie, Julia, Maria, Marilia e Solange.
} 
dificultado o acesso ao domínio pleno da forma de olhar institucionalizada numa linguagem formal, dominante, aprende a reconhecer outros sinais que não apenas os explícitos nessa linguagem.

Desconhecendo as leis que regera uma realidade da qual participa lateralmente, ela aprende a guiar-se nesse mundo obscuro seguindo pistas que obedecem a uma lógica diferente daquela que ordena a linguagem explícita. Se as relações formais da sociedade lhe são acessíveis apenas através dos homens, portanto de maneira incompleta, será também através de vias informais que ela terá uma visão dessas relações. Não é preciso enfatizar a importância da fofoca como uma, dessas vias informais. Mas se muito já se disse sobre sua importância social, pouco se fala sobre sua aprendizagem pelas mulheres, ou sobre sua, contribuição específica a partir da observação que fazemos de detalhes aparentemente não relevantes, mas que se constituirão no conteúdo privilegiado da fofoca.

Quando e como uma mulher nesta situação aprende o que com outras mulheres, quais os elementos relevantes a selecionar por trás, por baixo ou ao lado dos elementos formalmente explícitos numa relação? Como se decompõem as várias impressões sobre o tom de voz, o gesto, a postura, a localização espacial dos interlocutores que, articulados, se oferecem como uma unidade, como uma intuição - assim como poderíamos decompor sentenças em palavras, sílabas e letras? Não falo dos profissionais na análise de pessoas que institucionalizam este método, codificam estes elementos e os transmitem de forma organizada. Trata-se de algo mais fluido, mais afetado por diferentes experiências concretas, mais contextualizado e, portanto mais dinâmico.

Porque relegamos sempre ao quintal do conhecimento este tipo de percepção e nos mesmas nos referimos a ele como 'intuição feminina'? Há várias possibilidades de começar a pensar sobre esta questão. Em primeiro lugar, como distinguir a linguagem explícita da implícita, se elas aparecem fortemente entrelaçadas? A distinção provavelmente se torna mais fácil de 
perceber quando há uma disjunção entre elas. Como alguém exemplificou em nosso seminário, se uma pessoa chega e te dá um beijo e diz "como vai, meu amor", com um tom de voz ou uma expressão gestual, corporal, que contradiz suas palavras, um conhecimento mínimo de leitura do implícito (à falta de termo melhor) torna claro o descolamento entre ambas as linguagens. $\mathrm{Ou}$, se elas parecem coincidir, pode-se imaginar uma situação na qual o desconhecimento da lógica de articulação da linguagem utilizada por um dos interlocutores faça com que a linguagem implícita seja a única via de acesso à compreensão.

Isto implica em que existe algum tipo de conhecimento da situação dada ou a compreensão dela seria de todo impossível. ${ }^{9}$ Penso num diálogo entre uma patroa e sua empregada domestica, por exemplo, ou entre uma criança e um adulto. Se os termos utilizados na formulação de uma ordem doméstica, maternal ou escolar, escapam ao entendimento da empregada ou da criança, elas se guiarão pelo tom dessa voz, pela expressão do rosto de quem a dá, sua postura, etc. O que nos leva, claro, à questão das relações de poder.

Poderíamos argumentar então que chamar essa leitura de implícitos de 'intuição feminina' é restringir o alcance de um nível de percepção que é sempre desenvolvido pelo lado mais fraco de uma relação, o que não tem acesso à linguagem dominante. $\mathrm{A}$ quem está no poder não interessa se seu subordinado diz "sim senhor" de boa ou má cara, ao subordinado sim interessa ter plena consciência dos humores de seu chefe. O que não significa que o chefe não teria acesso a esta linguagem, a estes sub-tons da relação, mas que pode se dar ao luxo de desconhecê-los.

Aqui voltamos à complicada distinção entre o masculino e o feminino, tão difícil de explicitar como esta percepção do não dito. Ou talvez não: se se pode falar, outra vez entre aspas, de uma cultura masculina - exemplificada na aprendizagem que os

\footnotetext{
9 As belas fotos do ensaio de Bateson/Mead sobre o uso do corpo na sociedade balinesa são ao mesmo tempo exemplo disso e também de como ainda utilizamos, nessa interpretação do outro, elementos da nossa própria linguagem.
} 
meninos de nossa sociedade fazem de marcas de automóveis ou de nomes de jogadores de futebol, para ficar no aparente - podese também pensar numa "cultura feminina". Isto é, na aprendizagem, desde muito cedo, deste olhar enviesado $e$ doméstico que se constitui a sombra de um olhar que tem o mundo como horizonte. O que não quer dizer que as crianças em geral - meninos e meninas - não tenham a experiência do aprendizado deste olhar quando ainda unidos enquanto crianças frente a um mundo adulto. Mas para o menino talvez seja mais fácil 'esquecê-lo' uma vez que ganha acesso a uma outra via de conhecimento, a um outro olhar, mais direto e mais abrangente, $e$ uma vez que este não é um modo de olhar legitimo para homens: 'coisa de mulher', 'fofoca'. Assim qualificado, este olhar não pertence à linguagem masculina em nossa sociedade. Mas enquanto parte da linguagem feminina, não é sequer um verbo ainda e talvez também a maneira de falar sobre isso que denominamos imperfeitamente de intuição feminina seja necessariamente enviesada, aproximada, tentativa.

\section{Referências}

G. BATESON e M. MEAD. Balinese Character, a photographic analysis. N.Y., 1942

G. BATESON. Steps to an ecology of mind, London, 1973

L. BOLTANSKI. As Classes Sociais e o Corpo, Graal, Rio, 1979

P. BOURDIEU. "Remarques provisoires sur la perception sociale du corps", Actes de La Recherche en Sciences Sociales (14), avril, 1977

C. R. BOXER. Mary and Misogyny- women in Iberian expansion overseas, 1415-1815, some facts, fancies and personalities, London, 1975

M. CORRÊA. Os atos e os autos, representações jurídicas de papéis sexuais, mimeo, Campinas, 1975

P. CLASTRES. "De la torture dans la sociétés primitives", L'Homme, XIII:31 (A Sociedade contra o Estado, Francisco Alves, Rio, 1978) 
G. DELEUZE. Differénce et Répétition, Paris, 1972

L. DUMONT. Homo Hierarchicus, Paris, 1967.

Homo Aequalius, Paris, 1977.

M. FOUCAULT. Vigiar e Punir, nascimento da prisão, Graal, Rio, 1977

A Vontade de Saber, Cultrix, Rio, 1978.

N. FRIDAY. My Secret Garden- Women's sexual fantasies, N.Y., 1973

P.FRY. "As vantagens de ser bruxa", Boletim do Conjunto de Antropologia da ÜNICAMP (2), 1974

M. GLUCKMAN. "Gossip \& Scandal", Current Anthropology, 4:3 junho de 1963

H. GARFIHKEL. Studies in_Ethnomethodology, N.J., 1967

E. GOFFMAN. The Presentation of Self in Everyday Life, N.Y., 1959

Interaction Ritual- essays on face-to-face behavior, N.Y., 1967

E. LEACH. "Virgin Birth" in Gênesis as Myth and other essays, London, 1969

D. LESSING. The Four-Gated City, N.Y., 1969

M.MAUSS. "As técnicas corporais". Sociologia e Antropologia, vol.II, ed.Pedagógica e Universitária/Edusp, SP, 1974 